\title{
Chronological Comparison on Productivity for the Assessment of the Department of Health -Affiliated Hospitals in Taiwan - Application of Malmquist Productivity Index
}

\author{
Ching-Kuo Wei
}

\begin{abstract}
This study used Malmquist Productivity Index and Bilateral Model to investigate the performance of productivity of the DOH (Department of Health)-affiliated in Taiwan in chronological order. The results showed that most of the DOH-affiliated hospitals experienced a progress in efficiency performance, technological transformation, and overall productivity from 2005 to 2006 . However, there was a regress in all of them from 2006 to 2007. The reduction in production technology was mainly affected by NHI policies and the change in the management system of the DOH. However, according to the two-year comparison, there was still a progress in 2007, compared with that in 2005. Moreover, there was no significant difference in the operational efficiency between the two regional alliance systems divided by the DOH.
\end{abstract}

Index Terms-Malmquist productivity index, bilateral model , DOH-affiliated hospitals.

\section{INTRODUCTION}

Among the public hospital system in Taiwan, the DOH-affiliated hospitals provide the widest services and outnumber other public hospitals. At present, there are a total of $22 \mathrm{DOH}$-affiliated hospitals providing emergency service. The DOH-affiliated hospitals are distributed everywhere in Taiwan, and are almost available in each County/City. Therefore, their advantages are the robust medical care network and medical care access.

However, since the Bureau of National Health Insurance promoted global budget payment system in 2004, various medical institutions started to face the floating point value of the national health insurance (NHI), leading to the significant reduction in medical income. Moreover, with the decrease in economic growth, openness of information, rapid growth of private hospitals, and gradual decrease in governmental subsidy, the productivity of the DOH-affiliated hospitals has significantly decreased. Therefore, the chronological analysis on productivity index can provide reference value for the operation of the DOH-affiliated hospitals and help establish development strategies.

Many researchers have applied Data Envelopment Analysis (DEA) models to study hospital efficiency [1]-[5]. However, most researches focused on cross-section data analysis, and seldom discussed the impact on hospital efficiency before and after implementing a major policy. In general, all DEA studies would consider performance

Manuscript received September 17, 2012; revised November 14, 2012.

Ching-Kuo Wei is with the Oriental Institute of Technology, New Taipei City, Taiwan. (e-mail: f1003@mail.oit.edu.tw). analysis at a given point of time. However, extensions to the standard DEA procedures, such as the Malmquist Productivity Index (MPI) approach, have been reported to provide Productivity analysis in a time-series setting [6]-[8].

Many studies have investigated the application of Malmquist model to medical care-related industry [9]-[16]. As a whole, the chronological analysis of changes in productivity mainly investigated three aspects (indices): efficiency change, technological transformation, and MPI to compare the multi-year production efficiency. Therefore, this study used Malmquist model to discuss the change in multi-year productivity of the DOH-affiliated hospitals in Taiwan.

\section{METHOD}

\section{A. Malmquist Productivity Index (MPI)}

The framework employed in the current study can be illustrated by Figure 1 following Fare et al. In this diagram, a production frontier representing the efficient level of output (y) that can be produced from a given level of input (x) is constructed, and the assumption made that this frontier can shift over time. The frontiers thus obtained in the current $(\mathrm{t})$ and future $(\mathrm{t}+1)$ time periods are labelled accordingly. When inefficiency is assumed to exist, the relative movement of any given council over time will therefore depend on both its position relative to the corresponding frontier (technical efficiency) and the position of the frontier itself (technical change). If inefficiency is ignored, then productivity growth over time will be unable to distinguish between improvements that derive from a council 'catching up' to its own frontier, or those that result from the frontier itself shifting up over time.

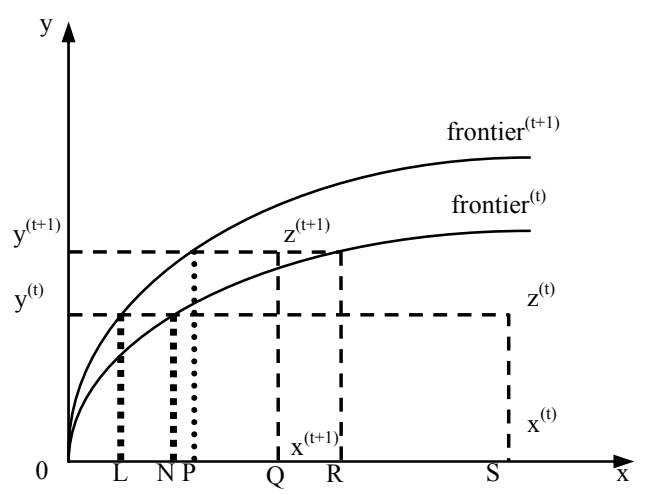

Fig. 1. Malmquist Index and productivity changes over time 
Now for any given council in period $t$, say, represented by the input/output bundle $z(t)$, an input-based measure of efficiency can deduced by the horizontal distance ratio $0 \mathrm{~N} / 0 \mathrm{~S}$. That is, inputs can be reduced in order to make production technically efficient in period t (i.e. movement onto the efficient frontier). By comparison, in period $t+1$ inputs should be multiplied by the horizontal distance ratio $0 \mathrm{R} / 0 \mathrm{Q}$ in order to achieve comparable technical efficiency to that found in period $t$. Since the frontier has shifted, $0 \mathrm{R} / 0 \mathrm{Q}$ exceeds unity, even though it is technical inefficient when compared to the period $t+1$ frontier. It is possible using the Malmquist input-based productivity index to decompose this total productivity change between the two periods into technical change and technical efficiency change. An input-based productivity index is used since it is generally argued that an input- orientation is consistent with the notion that local government outputs are largely given and the focus is on reducing inputs (proportionately) as much as possible, given technology.

The input-oriented Malmquist productivity change index can be written as:

$M_{I}^{t+1}\left(y^{t+1}, x^{t+1}, y^{t}, x^{t}\right)=\left[\frac{D_{I}^{t}\left(y^{t+1}, x^{t+1}\right)}{D_{I}^{t}\left(y^{t}, x^{t}\right)} \times \frac{D_{I}^{t+1}\left(y^{t+1}, x^{t+1}\right)}{D_{I}^{t+1}\left(y^{t}, x^{t}\right)}\right]^{1 / 2}$

where $D_{I}^{t}$ is a distance function measuring the efficiency ofconversion of inputs $x^{t}$ to outputs $y^{t}$ in the period $t$. DEA efficiencies have been considered as distance measure as it reflects the efficiency of conversion of inputs to outputs .

Note that if there is a technological change in the period $(\mathrm{t}+1)$, then:

$D_{I}^{t+1}\left(y^{t}, x^{t}\right)=$ Efficiency of conversion of input at period $t$ to output at period $t \neq D_{I}^{t}\left(y^{t}, x^{t}\right)$

Malmquist productivity index (MPI) can be written as:

$$
M_{I}^{t+1}\left(y^{t+1}, x^{t+1}, y^{t}, x^{t}\right)=\frac{D_{I}^{t+1}\left(y^{t+1}, x^{t+1}\right)}{D_{I}^{t}\left(y^{t}, x^{t}\right)}\left[\frac{D_{I}^{t}\left(y^{t+1}, x^{t+1}\right)}{D_{I}^{t+1}\left(y^{t+1}, x^{t+1}\right)} \times \frac{D_{I}^{t}\left(y^{t+1}, x^{t+1}\right)}{D_{I}^{t+1}\left(y^{t}, x^{t}\right)}\right]^{1 / 2}
$$

or

where

$$
\begin{gathered}
M=E \times T \\
E=\frac{D_{I}^{t+1}\left(y^{t+1}, x^{t+1}\right)}{D_{I}^{t}\left(y^{t}, x^{t}\right)}, \\
T=\left[\frac{D_{I}^{t}\left(y^{t+1}, x^{t+1}\right)}{D_{I}^{t+1}\left(y^{t+1}, x^{t+1}\right)} \times \frac{D_{I}^{+1 t}\left(y^{t}, x^{t}\right)}{D_{I}^{+1 t}\left(y^{t}, x^{t}\right)}\right]^{1 / 2}
\end{gathered}
$$

where $E$ is Efficiency Change, and $T$ is Technology change. If the Malmquist Productivity Index and its components are greater than 1 , equal to 1 , or less than 1 , they indicate progress, no change, or regress, respectively.

\section{B. Bilateral Model}

Tone proposed Bilateral mode to calculate efficiencies of two different sets of DMUs groups, where the efficiency value of efficient DMUs is larger than 1, and then apply Rank-Sum-Test to detect which group owns better efficiency. Bilateral mode's linear programming is as follows (where I and II represent two sets of DMUs groups respectively):

$$
\begin{array}{ll}
\text { Min } & \theta \\
\text { s.t. } & \sum_{j \in \Pi} X_{j} \lambda_{j} \leq \theta X_{k}, k \in \mathrm{I}, \\
& \sum_{j \in \Pi} Y_{j} \lambda_{j} \geq \theta Y_{k}, k \in \mathrm{I}, \\
& \lambda_{j} \geq 0(\forall j \in \Pi)
\end{array}
$$

\section{DATA ANALYSIS}

This study collected data from "Survey on the Status of Hospitals and their Service Volume in Taiwan" in 2005 to 2007, from the Department of Health. According to the statistics, in each year, there are 22 hospitals in this study. Input items and output items are selected in Table I

TABLE I: DEFINITION AND EXPLANATION OF VARIABLES

\begin{tabular}{ll}
\hline \hline Variables & Definition and explanation \\
\hline Inputs & $\begin{array}{l}\text { The total number of registered beds within the hospital, } \\
\text { Beds }\end{array}$ \\
& including acute, chronic, and special beds
\end{tabular}

Physicians The total number of physicians who are full-time employees, including dentists and Chinese medicine doctors

Paramedical The total number of health service providers employed in Personnel the hospitals, including pharmacists, dietitians, physiotherapists, occupational therapy technologists, and radiological technologist

Nurses

The total number of nurses employed in the hospitals

\begin{tabular}{|c|c|c|c|c|c|c|c|}
\hline & Beds & Physicians & Nurses & $\begin{array}{l}\text { Paramedical } \\
\text { Personnel }\end{array}$ & Patient days & Operations & Outpatients \\
\hline Max & 982 & 144 & 496 & 191 & 187090 & 11091 & 672346 \\
\hline Min & 52 & 7 & 29 & 9 & 4518 & 342 & 40897 \\
\hline Average & 458 & 58 & 227 & 65 & 89556 & 3831 & 303254 \\
\hline SD & 232 & 42 & 145 & 44 & 44348 & 3168 & 198896 \\
\hline Beds & 1 & 0.769 & 0.873 & 0.835 & 0.867 & 0.749 & 0.780 \\
\hline Physicians & & 1 & 0.930 & 0.870 & 0.806 & 0.917 & 0.952 \\
\hline Nurses & & & 1 & 0.932 & 0.888 & 0.905 & 0.911 \\
\hline $\begin{array}{l}\text { Paramedica } \\
1 \\
\text { Personnel }\end{array}$ & & & & 1 & 0.782 & 0.796 & 0.876 \\
\hline Patient days & & & & & 1 & 0.855 & 0.798 \\
\hline Operations & & & & & & 1 & 0.913 \\
\hline Outpatients & & & & & & & 1 \\
\hline
\end{tabular}

Outputs

Patient days The total admission days of inpatient care within a year Operations The total number of inpatient and outpatient surgeries within a year

Outpatients The total number of patients to emergency rooms and Services outpatient departments (OPD) within a year

TABLE II: DESCRIPTIVE STATISTICS AND CORRELATION

Table II is the descriptive statistics and correlation matrix. There is a highly positive correlation between the inputs and outputs, indicating that increasing one unit of the input will increase one unit of output accordingly. It is in accordance with the hypothesis of constant returns to scale. And in order to examine whether hospitals have tried their best to reduce the input of resources while maintaining the same level of output, this study applied the input oriented model with constant returns to scale assumption for analysis. 


\section{RESULTS}

In the chronological comparison of efficiency, Malmquist Productivity Index (MPI) is most frequently used in studies. MPI $=$ efficiency change $*$ technological transformation. When the efficiency value $>1$, there is a progress in productivity. When it $=1$, there is no change in productivity. When it $<1$, there is a regress in productivity.

\section{A. Analysis of Efficiency Change}

As shown in Table III, the value of efficiency change of hospital A from 2005 to 2006 was $0.972(<1)$, suggesting that the production efficiency of hospital A in 2006 declined, compared with that in 2005 . The value of efficiency change of hospital B from 2005 to 2006 was $1.247(>1)$, suggesting that there was a progress in the production efficiency of hospital B in 2006, compared with that in 2005. Therefore, the efficiency performance of hospital A declined year by year, suggesting that the production efficiency of hospital A was poor. Hospital A should review their disadvantages and make improvements; otherwise, they will face the difficulty in operation. The situation of hospital $\mathrm{C}$ was different. The value of efficiency change of hospital $\mathrm{C}$ was $>1$, suggesting that there was a progress in the production efficiency of hospital $\mathrm{C}$ year by year. Therefore, the efficiency performance of hospital $\mathrm{C}$ was ideal. Moreover, the efficiency change of hospital R from 2005 to 2007 was $=1$, suggesting that there was no change (progress or regress) in hospital R.

TABLE III: ANALYSIS IN EFFICIENCY CHANGE

\begin{tabular}{|c|c|c|c|}
\hline DMUs & $2005=>2006$ & $2006=>2007$ & $2005=>2007$ \\
\hline A & 0.972 & 0.963 & 0.937 \\
\hline B & 1.247 & 0.769 & 0.959 \\
\hline $\mathrm{C}$ & 1.207 & 1.005 & 1.213 \\
\hline $\mathrm{D}$ & 0.947 & 1.049 & 0.993 \\
\hline $\mathrm{E}$ & 1.121 & 0.998 & 1.119 \\
\hline $\mathrm{F}$ & 1.345 & 0.912 & 1.227 \\
\hline G & 0.981 & 0.997 & 0.978 \\
\hline $\mathrm{H}$ & 1.198 & 1.007 & 1.206 \\
\hline I & 1.088 & 1.048 & 1.139 \\
\hline $\mathrm{J}$ & 1.361 & 0.968 & 1.318 \\
\hline $\mathrm{K}$ & 1.135 & 0.972 & 1.104 \\
\hline $\mathrm{L}$ & 1.069 & 1.095 & 1.171 \\
\hline M & 1.213 & 0.870 & 1.055 \\
\hline $\mathrm{N}$ & 0.752 & 0.944 & 0.710 \\
\hline $\mathrm{O}$ & 0.888 & 1.001 & 0.889 \\
\hline $\mathrm{P}$ & 0.927 & 1.089 & 1.009 \\
\hline Q & 1.028 & 1.051 & 1.080 \\
\hline $\mathrm{R}$ & 1.041 & 0.960 & 1.000 \\
\hline $\mathrm{S}$ & 0.793 & 1.021 & 0.810 \\
\hline $\mathrm{T}$ & 1.096 & 0.893 & 0.979 \\
\hline $\mathrm{U}$ & 0.641 & 1.034 & 0.663 \\
\hline V & 1.059 & 0.953 & 1.009 \\
\hline
\end{tabular}

\section{B. Analysis in Technological Transformation}

As shown in Table IV, the value of technological transformation of hospital A from 2005 to 2006 was $1.325(>1)$, suggesting that there was a progress in the production technology of hospital A in 2006, compared with that in 2005. However, there was a regress from 2006 to 2007 (0.829). From 2005 to 2007, there was still a progress (1.198). As shown in Table 5, an interesting phenomenon was found. There was a progress in the technological transformation in all the DOH-affiliated hospitals from 2005 to 2006 . However, from 2006 to 2007, there was a regress in all of them. In terms of the two-year observation, there was a progress from 2005 to 2007. The phenomenon might be associated with the NHI policies or the change in management of the $\mathrm{DOH}$, which led to the technological transformation of all the hospitals in the external environment.

TABLE IV: ANALYSIS IN TECHNOLOGICAL TRANSFORMATION

\begin{tabular}{|c|c|c|c|}
\hline DMUs & $2005=>2006$ & $2006=>2007$ & $2005=>2007$ \\
\hline A & 1.325 & 0.829 & 1.198 \\
\hline B & 1.356 & 0.933 & 1.413 \\
\hline $\mathrm{C}$ & 1.144 & 0.956 & 1.033 \\
\hline $\mathrm{D}$ & 1.729 & 0.882 & 1.576 \\
\hline $\mathrm{E}$ & 1.613 & 0.823 & 1.458 \\
\hline $\mathrm{F}$ & 1.463 & 0.849 & 1.343 \\
\hline G & 1.624 & 0.842 & 1.434 \\
\hline $\mathrm{H}$ & 1.451 & 0.944 & 1.271 \\
\hline I & 1.309 & 0.935 & 1.242 \\
\hline $\mathrm{J}$ & 1.175 & 0.868 & 1.103 \\
\hline K & 1.586 & 0.861 & 1.320 \\
\hline $\mathrm{L}$ & 1.833 & 0.811 & 1.562 \\
\hline M & 1.786 & 0.781 & 1.543 \\
\hline $\mathrm{N}$ & 1.930 & 0.800 & 1.761 \\
\hline $\mathrm{O}$ & 1.320 & 0.878 & 1.193 \\
\hline $\mathrm{P}$ & 1.715 & 0.853 & 1.557 \\
\hline Q & 1.303 & 0.941 & 1.225 \\
\hline $\mathrm{R}$ & 1.787 & 0.710 & 1.542 \\
\hline $\mathrm{S}$ & 1.439 & 0.804 & 1.349 \\
\hline $\mathrm{T}$ & 1.486 & 0.806 & 1.340 \\
\hline $\mathrm{U}$ & 1.364 & 0.819 & 1.294 \\
\hline V & 1.472 & 0.869 & 1.337 \\
\hline
\end{tabular}

\section{Analysis in MPI}

The analysis of the MPI of the DOH-affiliated hospitals is shown in Table V. The MPI value of hospital A from 2005 to 2006 was $1.289(>1)$, suggesting that there was a progress in the production technology in hospital A, compared with that in 2005. However, there was a regress from 2006 to 2007 (0.798). In terms of the two-year observation, there was still a progress from 2005 to 2007 (1.122). There was a regress in the change in efficiency of hospital A, compared with that in the previous year $(0.972)$. However, there was a progress in technological transformation (1.325). Under the influence of the two factors, there was still a progress in MPI of hospital A. Therefore, this study found that the progress in MPI of hospital A was mainly associated with the improvement of production technology. Owing to the change in production technology, among all the DOH-affiliated hospitals, only the MPI of hospital U from 2005 to 2006 declined, while there was a progress in that of the rest of them. From 2006 to 2007 , owing to the regress in the production technology, there was a regress in the MPI of all the DOH-affiliated hospitals in 
2007. In terms of the 2-year observation, from 2005 to 2007, there was a regress in the MPI of hospital U. However, there was a progress in the MPI of all the DOH-affiliated hospitals. Consequently, the decline of MPI of hospital U year by year was noteworthy.

\begin{tabular}{cccc}
\multicolumn{4}{c}{ TABLE V: ANALYSIS IN MPI } \\
\hline \hline DMUs & $2005=>2006$ & $2006=>2007$ & $2005=>2007$ \\
\hline $\mathrm{A}$ & 1.289 & 0.798 & 1.122 \\
$\mathrm{~B}$ & 1.691 & 0.718 & 1.355 \\
$\mathrm{C}$ & 1.380 & 0.960 & 1.253 \\
$\mathrm{D}$ & 1.638 & 0.925 & 1.566 \\
$\mathrm{E}$ & 1.809 & 0.821 & 1.632 \\
$\mathrm{~F}$ & 1.968 & 0.775 & 1.648 \\
$\mathrm{G}$ & 1.593 & 0.840 & 1.402 \\
$\mathrm{H}$ & 1.738 & 0.950 & 1.532 \\
$\mathrm{I}$ & 1.424 & 0.980 & 1.416 \\
$\mathrm{~J}$ & 1.600 & 0.840 & 1.454 \\
$\mathrm{~K}$ & 1.800 & 0.837 & 1.457 \\
$\mathrm{~L}$ & 1.959 & 0.888 & 1.829 \\
$\mathrm{M}$ & 2.167 & 0.679 & 1.627 \\
$\mathrm{~N}$ & 1.451 & 0.755 & 1.250 \\
$\mathrm{O}$ & 1.172 & 0.879 & 1.060 \\
$\mathrm{P}$ & 1.589 & 0.929 & 1.570 \\
$\mathrm{Q}$ & 1.340 & 0.989 & 1.324 \\
$\mathrm{R}$ & 1.860 & 0.682 & 1.541 \\
$\mathrm{~S}$ & 1.142 & 0.820 & 1.092 \\
$\mathrm{~T}$ & 1.629 & 0.720 & 1.311 \\
$\mathrm{U}$ & 0.874 & 0.847 & 0.858 \\
$\mathrm{~V}$ & 1.559 & 0.828 & 1.348 \\
\hline \hline
\end{tabular}

\section{Analysis on Hospitals Change in MPI}

As shown in Table VI, in terms of change in efficiency, there was a progress in 14 hospitals (63.6\%) from 2005 to 2006, while there was a regress in 8 hospitals (36.4\%). Therefore, most of the hospitals (54.5\%) experienced a progress in production efficiency from 2005 to 2007. In terms of technological transformation, in 2007, owing to the impact of the NHI policies and change in management of the $\mathrm{DOH}$, there was a progress in all the hospitals from 2005 to 2006, while there was a regress in all of them from 2006 to 2007. As for MPI, only the MPI of hospital U declined year by year, while that of the rest of the hospitals changed with the change in production technology.

TABLE VI: ANALYSIS ON HoSPITALS CHANGE IN MPI

\begin{tabular}{llrrrrrr}
\hline \hline & & \multicolumn{2}{c}{$2005=>2006$} & $2006=>2007$ & $2005=>2007$ \\
& & $\mathrm{~N}$ & $\%$ & $\mathrm{~N}$ & $\%$ & $\mathrm{~N}$ & $\%$ \\
\hline Efficiency & progress & 14 & 63.6 & 10 & 45.5 & 12 & 54.5 \\
& no change & 0 & 0 & 0 & 0 & 1 & 5 \\
& regress & 8 & 36.4 & 12 & 54.5 & 9 & 40 \\
\multirow{3}{*}{ Technology } & progress & 22 & 100 & 0 & 0 & 22 & 100 \\
& regress & 0 & 0 & 22 & 100 & 0 & 0 \\
MPI & progress & 21 & 95 & 0 & 0 & 21 & 95 \\
& regress & 1 & 5 & 22 & 100 & 1 & 5 \\
\hline \hline
\end{tabular}

\section{E. Comparison Productivity of Alliance Hospitals}

In order to improve the medical care service quality of the DOH-affiliated hospitals, the DOH divided hospitals into two regional alliances, hospitals in the northern Taiwan and hospitals in the central and southern Taiwan, according to regional, functional, and complementary characteristics, to facilitate the sharing of medical care resources and to achieve the objectives of improving operational performance and overall competitiveness. Therefore, this study particularly compared the two alliance systems, alliance hospitals in the northern Taiwan and alliance hospitals in the central and southern Taiwan. The calculations using Bilateral model are shown in Table VII. After the Rank-sum-test was performed, this study found that the difference between the two medical systems $(\mathrm{P}$ value $=0.065)$ was not significant, suggesting that the operational efficiency of the alliance hospitals in the northern Taiwan was not different from that of those in the central and southern Taiwan.

TABLE VII: Comparison Productivity of Alliance Hospitals

\begin{tabular}{|c|c|c|}
\hline Group & Northern & Central and Southern \\
\hline No. of DMUs & 10 & 12 \\
\hline Average & 1.036 & 1.274 \\
\hline SD & 0.215 & 0.356 \\
\hline Maximum & 1.582 & 1.877 \\
\hline Minimum & 0.738 & 0.659 \\
\hline Rank-Sum Test & \multicolumn{2}{|c|}{1.517} \\
\hline P-Value & \multicolumn{2}{|c|}{0.065} \\
\hline
\end{tabular}

\section{CONCLUSION}

This study investigated the productivity performance of the DOH-affiliated hospitals in chronological order. The results showed that most of the DOH-affiliated hospitals experienced a progress in efficiency performance, technological transformation, and overall productivity from 2005 to 2006 . However, there was a regress in all of them from 2006 to 2007 . The reduction in production technology was mainly affected by NHI policies and the change in the management system of the DOH. However, according to the two-year comparison, there was still a progress in 2007, compared with that in 2005 . As a whole, only hospital $U$ had an urgent need for improvement, while the rest of the DOH-affiliated hospitals all improved. Moreover, there was no significant difference in the operational efficiency between the two regional alliance systems divided by the DOH.

The DOH-affiliated hospitals are the most important alliance hospitals in the public hospital system. Therefore, they have to improve operational efficiency and competitiveness. In the current extremely competitive medical environment, the DOH-affiliated hospitals have to improve their operational efficiency to acquire competitiveness. Because the current DOH-affiliated hospital alliances have achieved a preliminary effect, it is necessary to expand the cooperation mechanism and make adjustments according to the difference in hospitals. The DOH-affiliated hospitals have implemented regional alliances in order to improve the service level and operational 
performance of hospitals based on resource sharing, technological exchange, and joint marketing model. Moreover, they also intend to implement market segmentation and inter-hospital technological exchange according to the expertise and characteristics of hospitals, in order to achieve the effect of alliance for mutual learning and growth. Furthermore, it is necessary for them to establish the performance objective, to analyze the competitiveness of medical market, to reduce cost, and to enhance competitiveness, in order to understand their own disadvantages and win the victory.

\section{REFERENCES}

[1] H. D. Sherman, "Hospital Efficiency Measurement and Evaluation," Medical Care, vol.22, pp. 922-938, 1984.

[2] G. D. Ferrier and V. Valdmanis, "Rural hospital performance and its correlates," The Journal of Productivity Analysis, vol.7, pp. 63-68, 1996.

[3] H. H. Chang, "Determinants of hospital efficiency: The case of central government-owned hospital in Taiwan," Omega, vol.26, no.2, pp. 307-317, 1998.

[4] Y. A. Ozcan., D. L. Roice, and C. Haksaver, "Ownership and organizational performance: A comparison of technical efficiency across hospital types," Medical Care, vol.30, no.9, pp. 781-794, 1992.

[5] R. R. Bannick, and Y.A. Ozcan, "Efficiency analysis of federally funded hospital: comparison of DOD and VA hospital using data envelopment analysis, Health Services Management Research, vol.8, no. 5 , pp. $73-85,1995$.

[6] A. Charnes, W.W. Cooper, A.Y. Lewin, and L. M. Seiford, "Data Envelopment Analysis: Theory, Methodology and Applications," Kluwer, Boston, MA, 1994.

[7] J. Burgess and P. Wilson, "Decomposing Hospital Productivity Changes, 1985-1988: A Nonparametric Malmquist Approach," Journal of Productivity Analysis, vol.6, pp.343-363, 1995.
[8] R. Färe, S. Grosskopf, B. Lindgren, and P. Roos, "Productivity Changes in Swedish Pharmacies 1980-1989: A Non-Parametric Malmquist Approach," The Journal of Productivity Analysis, vol.3, pp.85-101, 1992.

[9] R. Färe, S. Grosskopf, and P. Roos, "Productivity and Quality in Swedish Pharmacies", International Journal of Production Economics, vol.39, pp.137-147, 1995.

[10] T. W. Grosskopf and V. Valdmanis, "Measuring hospital performance: A non-parametric approach," Journal of Health Economics, vol.6, pp.89-107, 1987.

[11] Y. G. L. Huang, and C.P. McLaughlin, "Relative efficiency in rural primary health care: An application of data envelopment analysis," Health Services Research, vol.24, no.2, pp.143-158, 1989.

[12] M. Linna, "Measuring Hospital Cost Efficiency with Panel Data Models," Health Economics, vol.7, pp.415-427, 1998.

[13] R. Färe, S. Grosskopf, B. Lindgren, and P. Roos, "Productivity Changes in Swedish Pharmacies 1980-1989: A Non-Parametric Malmquist Approach," The Journal of Productivity Analysis, vol.3, pp.85-101, 1992.

[14] J. Magnussen, "Efficiency Measurement and the Operation of Hospital Production", Health Services Research, vol.31, pp.21-31, 1996.

[15] Wei Ching-kuo, "An Evaluation of Time-series Operational Performance on the Non-profit Hospitals in Taiwan," The Journal of American Academy of Business, vol.10, no.2, pp.173 178, 2007.

[16] Wei Ching-kuo, "Effects of a National Health Budgeting System on hospital performance: A case study;" International Journal of Management, vol.24 no.1, pp.33 24, 2007.

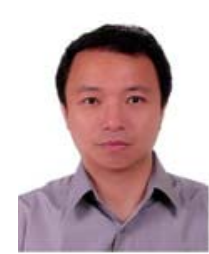

Ching-Kuo Wei, (PhD), Taipei, Taiwan.

Education: Institute of Health Policy and Management College of Public Health, National Taiwan University. His current position is Associate Professor and Director in the Dept. of Health Care Administration, Oriental Institute of Technology. 